\title{
Temperomandibular disorders Clinical and Modern Method In Differential Diagnosis
}

\author{
Dr Praveena K S ${ }^{1}$, DR Rathika rai ${ }^{2}$,Dr MA Easwaran ${ }^{3}$,Dr B Easwaran ${ }^{4}$ \\ ${ }^{1}$ P.G STUDENT Department of Prosthodontics, TMDCH, Dr.MGR Medcial University, Chennai TamilNadu, India \\ ${ }^{2}$ H.O.D Department of Prosthodontics, TMDCH, Dr. MGR Medcial University, Chennai TamilNadu, India \\ 3 senior lecturer Department of Prosthodontics TMDCH, Dr. MGR Medcial University, Chennai TamilNadu, India \\ ${ }^{4}$ senior lecturer Department of Prosthodontics TMDCH, Dr. MGR Medcial University, Chennai TamilNadu, India
}

\begin{abstract}
TMD disorders are a collective term for masticatory muscle and joint disorder. Diagnosis of this condition involves understanding of the pathology and cause and clinical features of the underlying disease. The aid of modern diagnostic techniques also gives us a good source of conformation. This article gives the insight into etiological factors and clinical conditions and other diagnostic methods, which are reliable in giving appropriate diagnosis.
\end{abstract}

Keywords: Temporomandibular Disorder, Masticatory Muscle Disorder, Orofacial Pain Disorders, Panoramic Radiography, Cone Beam Computer Tomography.

\section{Introduction}

Temperomandibular disorders include pain and dysfunction of masticatory muscles and the temperomandibular joint .It affects $20-30 \% 0 \mathrm{f}$ adult population to some degree and people affected are between $20-40 \mathrm{yrs}$ of age .It is the second most frequent cause of orofacial pain after dental pain .although it is not life threatening it can be detrimental to life .therefore appropropriate diagnosis with knoeledge of clinical features and and medica limaging provides a clue to proceed with the appropriate treatment .This article summarises on the temperomandibular disorders its clinical features and other orofacial disorders which mimic TMD disorders and different diagnostic imaging techniques which aid in diagnosis of TMD .

\section{Tmd - Temporomandibular Disorders}

According to the American Academy of Orofacial Pain,temporomandibular disorders are defined as 'a collective term embracing a number of clinical problems that involve the masticatory muscles, the TMJ, and associated structures, or both[1] .

TMD are a major cause of non-dental pain in the orofacial region and are considered a subclassification of musculoskeletal disorders[2].The primary signs and symptoms originate from the masticatory structures and therefore associated with jaw function and are a common source of chronic pain complaints in the head and orofacial structures. These complaints can be associated with some generalized musculoskeletal problems and even anxiety, and depression. Patients often report pain in the preauricular areas, face, or temples. Reports of pain during mouth opening or chewing are common. Some individuals may even report difficulty speaking or singing. TMJ sounds are also frequent complaints and maybe described as clicking, popping, grating, or crepitus. In many instances, the joint sounds are not accompanied by pain or dysfunction[3]. However, on occasion, joint sounds may be associated with locking of the jaw during opening or closing, or with pain. Patients may even report a sudden change in their bite coincident with the onset of the painful condition.It is important to appreciate that pain associated with most TMJ increased with jaw function. Because this is a condition of the musculoskeletal structures, function of these structures generally increases the pain. When a patient's pain complaint is not influenced by jaw function, other sources of orofacial pain should be suspected.. Based on the origin of pain TMJ disorders can be subdivided into masticatory muscle disorders and Temporomandibular joint disorders[4].

\section{Masticatory Muscle Disorder}

These arise due to functional disorders of masticatory muscles and are the most common cause of orofacial pain.they hae been considered to be analogous to skeletal muscle disorder in any other part of the body .It includes both regional or central mediated problems host susceptibility plays a major role in several stages of these disorders, including pain modulation and response to therapy .They must be identified and differentiated from temperomandibular joint disorders . 


\subsection{CLINICAL FEATURES}

Two main symptoms of TMD problems are pain and dysfunction .Pain, muscle tenderness ,limited range of motion and other symptoms, eg stiffness, subjective, fatigability .pain is diffuse and is bilateral and ranges from slight tenderness to discomfort .It is different from intra-capsular disorder where the pain is localized. The severity of muscle pain is generally, directly related to the amount of functional activityand towards the end of the day [5]. Therefore, patients often report that the pain affects their ability to open their mouth, chew, and speak. If the patient does not report an increase in pain associated with jaw function, the disorder is, not likely related to a masticatory muscle problem and other diagnoses should be considered.

Not all muscle pain is the same. Local muscle soreness is due to simple overuse of muscle and manifests as pain on palpation. Regional muscle pain ischaracterized by presence of firm hyperactive bands of muscle tissue, called trigger points. These create can be source of deep pain input can lead to central excitatory effects resulting in pain referral to surrounding or remote tissues. Pain sometimes is referred to the tooth and patient complains of tooth pain. In this site of pain is not the source of pain. Dentist is liable to miss the diagnosis muscle are not included in the examination. Therefore myofacial pain can lead to orofacial pain and correct diagnosis involved through history and examination .

Dysfunction is a common symptom in masticatory muscle disorder and characterized by decrease in range of motion. When muscle tissues have been compromised by overuse, any contraction or stretching increases the pain[6]. Therefore patient limits the movement within a range that does not produce discomfort. The restriction may also be partly due to contraction of the antagonistic muscles, a phenomenon that is called protective co-contraction. In many myalgic disorders the patient is able to slowly open wider but this increases the pain.

Acute malocclusion is associated with masticatory muscle disorder. Sudden change in the resting length of muscles, that control the jaw position can result in malocclusion and patient complaints of change of occlusal contacts. The mandibular position and resulting occlusal contacts depends on the muscle involved. If there is functional shortening of inferior lateral pterigoid is involved, there is disclusion of posterior tooth on ipsilateral side and premature contact of anterior especially the canine on the contralateral side[7]. Therefore it becomes necessary to understand that malocclusion is a result of muscle disorder and not the cause therefore treatment considerations should be aimed at treating the muscle disorder rather than correcting the occlusion .when the muscle disorder is resolved occlusion will return to normal .

\subsection{ETIOLOGICAL CONSIDERATIONS}

The etiological considerations In masticatory muscle disorder can be emotional stress .which lead to centrally mediated myalgia through antidromic activity leading to peripheral neurogenic inflammation. The pain can be influenced and actually initiated by the central nervous system through antidromic effects leading to neurogenic inflammation in the peripheral structures. When these peripheral structures are muscles it is felt as muscle pain this type of muscle pain is called centrally mediated myalgia and it becomes difficult for dentist to manage as teeth jaws and muscles are not the sources of pain. Some authors debate muscle pain is due to increased muscle useand accumulation ofmetabolic wasteproducts[6]. Activities such as daytime clenching of the teeth or sleep-relatedbruxing are common parafunctions that may lead to muscle pain[8]. It should be appreciated that these activities are common and do not lead to pain in most individuals . A misunderstood but very important concept for the clinician to appreciate is the fact that masticatory muscle pain is not strongly correlated with increased muscle activity such as in spasm[9-11]. studies reveal that the resting activity of the masticatorymuscles as measured by electromyography of patients with chronic muscle pain is no different than that of asymptomatic controls. Therefore the majority of masticatory muscle pain patients are not experiencing spasms.

\section{Temporomandibular Joint Disorders}

The signs associated with functional disorders of the TMJ are probably the most common findings when examining a patient for masticatory dysfunction.Joint disorders can fall into three broad categories

- Disorders- derangements of the condyle-disc complex.

- Structural incompatibility of the articular surfaces.

- Inflammatory joint disorders.

The first two categories have been collectively called disc interference disorders. The term discinterference disorder was first introduced by Welden Bell [12] to describe a category of functional disorders that arises from problems with the condyle-disc complex. These problems are due to a derangement or alteration of the attachment of the disc to the condyle; others to an incompatibility between the articular surfaces of the condyle, disc, and fossa; still others to the fact that relatively normal structures have been extended beyond their 
normal range of movement. With time, inflammatory disorders can arise from a localized response of the TMJ tissues to loading or trauma. These disorders are often the result of chronic or progressive derangement disorders.

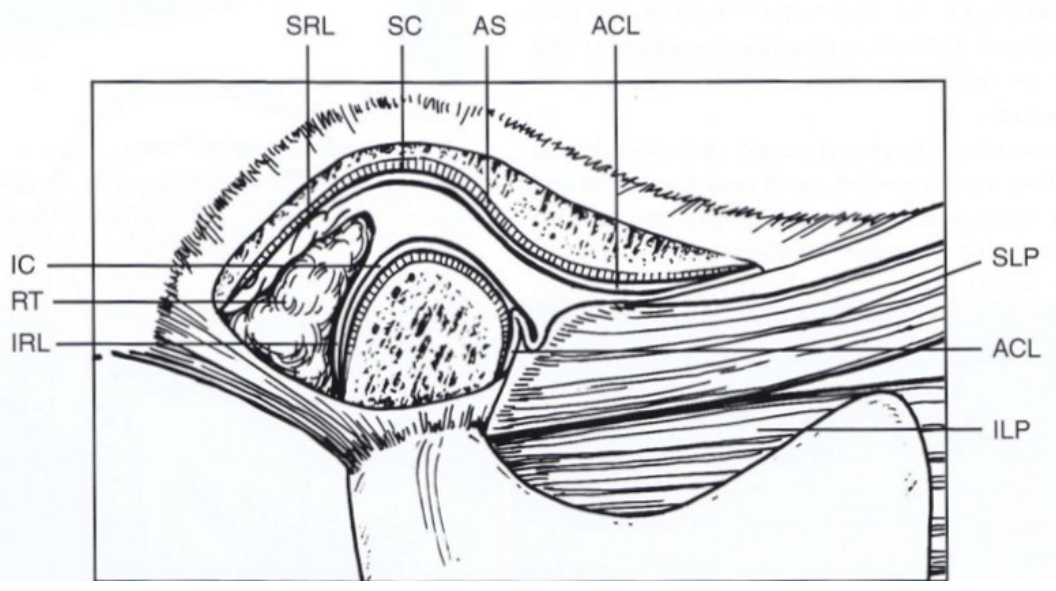

SRL-Superior retrodiscal tissue ,SC-superior cavity ,AS-articular surface ,ACL-anterior capsular ligament ,SLP-superior lateral pterigoid ,ILP-inferior lateral pterigoid ,IRL-inferior retro discal lamina ,RTretrodiscal tissue, IC-inferior joint cavity

\subsection{Clinical features}

The cardinal signs presenting signs of TMD include

- Limitation of jaw opening or function

- Pain with jaw opening or function

- Joint sounds

These may be considered as pain and dysfunction .Pain is sudden and sharp, it arise from mechanical abuse of healthy structures due to impingement of tissues or due to structures which are inflamed .Pain is sharp and sudden if it is due to mechanical abuse and is closely associated with joint movement then resolves instantly when joint is rested. Pain is dull and throbbing if it is due to inflammation, this type of pain is continuous even at rest and accentuated with joint movement. Pain is localized in the periauriculararea .

Dysfunction is disruption of the normal condyle-disc movement often with the production of joint sounds. It is related to joint movement . Joint sounds may be single event for a short duration such as click, or if is loud is generally referred to as pop. Crepitation is rough gravel like sound and is usually associated with inflammation.

A single click during opening of the mouth is often associated with an anterior displaced disc that is returned to a more normal position during the opening movement. This condition is referred to as a "disc displacement with reduction." Often when the patient closes the mouth a second click is felt which represents the re-displacement of the disc to the anterior displaced position. This single click is repeatable and if patient reports with loud crackling sound which is not repeatable than clinician should think of adherence [13]which is due to prolonged static loading of the join. Where lubrication is squeezed of the joint surfaces and they stick together ,this union is disrupted when the normal mouth opening resumes.

For some patients the disc displacement progresses and the disc may not be able to return to its normal relationship with the condyle during opening. This condition is referred to as a "disc displacement without reduction. When this occurs, the patient often cannot open fully because the disc is blocking the translation of the condyle. For condition is often referred to as a "closed lock". Additional clinical characteristics include a deflection to the ipsilateral side on opening and protrusion, and restriction of movement to the contralateral side due to the limited ability of the condyle to translate.

Crepitation is usually related to roughness of the articular surfaces because of remodeling or osteoarthritis present. It can also be a sign of perforation of the disc or the retrodiscal tissues. If crepitation is the only symptom or sign a patient presents with, treatment is not usually indicated. Similarly treatment is not indicated if the joint is associated with painless clicking. 


\subsection{ETIOLOGICAL CONSIDERATIONS}

The cause of intracapsular disorders of the TMJ is most commonly related to trauma[14-16]. This trauma may manifest itself as either macrotrauma or microtrauma. In cases of macrotrauma a single blow to the mandible can lead to a disruption of the normal biomechanical functions of TMJ. The traumatic event typically injures joint structures - elongating ligaments or damaging articular surfaces. Once ligaments have been elongated their biomechanical function is changed - often creating instability of the joint[17]. This could eventually lead to disc displacement, instability and disc displacement may both cause abnormal or unfavorable loading in the TMJ, and this may lead to osteoarthritic changes.

Microtrauma, a small amount of loading force repeated over a long period of time, may lead to changes in joint structures. When the teeth are brought into heavy contact and the joint structures are loaded, there is a momentary reduction of blood flow in the small capillaries that supply the joint structures, resulting in hypoxia (a reduced supply of oxygen). Under circumstances of hypoxia, the metabolism of the local cell populations may alter. The byproducts of the altered metabolism may form free radicals when oxygen becomes available again, once the load on the tissues is reduced [3].

Free radicals may also be generated by direct mechanical trauma and tissue damage. Free radicals are very unstable molecules with a strong affinity for electrons. If these electrons are taken from adjacent healthy tissues, the integrity of these tissues can be compromised. This process is known as a "hypoxia-reperfusion injury' [18].The changes include decrease in the lubrication quality or softening of the joint structures leading to chondromalacia. The compromised lubrication and softening of articular surfaces can cause the disc to displace from its normal position between the condyle and fossa. Once the disc is displaced joint loading can occur on the non-articular surface such as the retrodiscal tissue with further loading these tissues can break down allowing the condyle to directly load on the articular fossa, continuous loading can lead to loss of articular surfaces and the end result is osteoarthritis or degenerative joint disease.

\section{Other Common Orofacial Pain Disorders}

Pain in the orofacial structures is multifaceted and complex. Many of these painful conditions fall outside the realm of dental practice and should be referred to medical practitioners. Common orofacial pain conditions include

1. neuropathic pain

2. headache

Neuropathic pains are electric shock like quality pain followed by total remission, trigemenial neural gia is the most common of this type of pain and is brought about by innocuous stimuli such as touching the face shaving or brushing the tooth .

Headache may be unilateral type such as

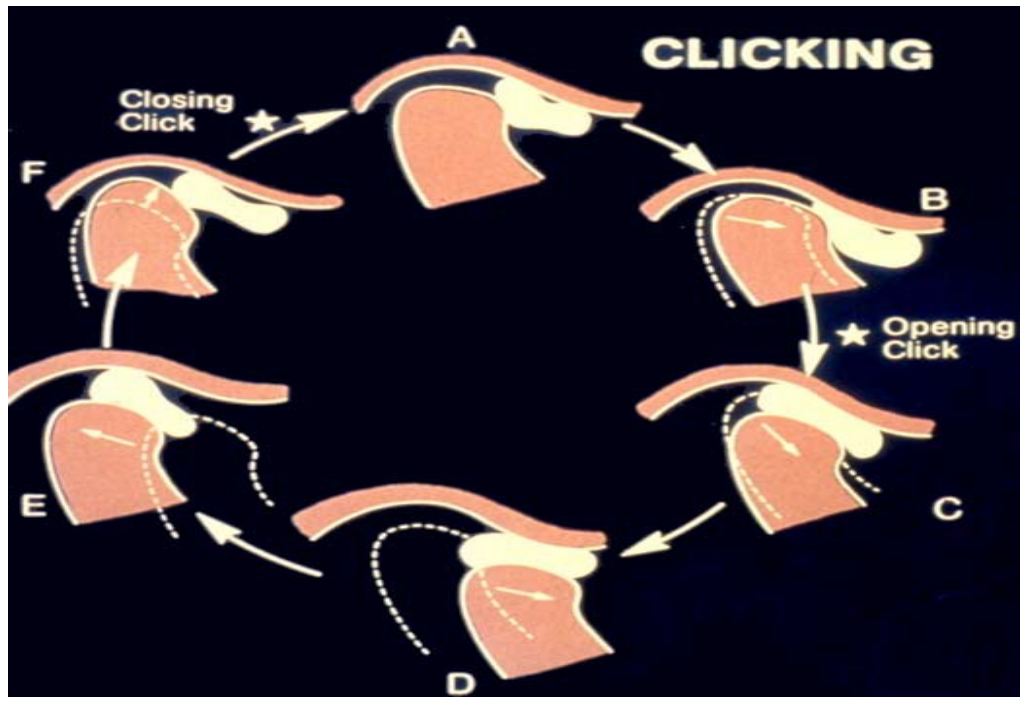

in migraine which is usually debilitating and lasting for a long duration tension type of headache are usually dull aching pain felt as tight band around the head. They are of mild to moderate intensity lasting for only a short duration .

\section{Non-Invasive Diagnostic Technique}

Diagnostic imaging, when indicated, is an important part of the examination process forTMD and orofacial pain patients. Imaging may be used to confirm suspected disease,rule-out disease, and gather additional information when the clinical diagnosis is unclear.Certain clinical presentations show positive findings on imaging such as reciprocal click, closed lock and crepitus [19].

\section{INDICATIONS FOR DIAGNOSTIC IMAGING OF TMJ \\ - Trauma \\ - Change in occlusion \\ - Limitation of opening / closed lock \\ - Presence of reciprocal click \\ - Crepitus}


- Systemic disease

- Swelling or infection

\section{PANORAMIC RADIOGRAPHY}

TMDsoften are associated with displacement of the disc along with arthritic and inflammatorychanges in the components of the TM joint .It is the basic study to be performed to all patients who present with the possible TMD . It helps to identify gross arthritic changes[20-22] or other hard tissue abnormalities such as tumor bone cysts or malformations of the mandibular condyle and surrounding glenoid fossa .It is a very good method of imaging both TMJ and other jaw and tooth structures. The projection of both joints with the mouth opened or closed in one film is convenient for the diagnosis of TMJ disorders. It is an alternative method for $\mathrm{X}-$ ray examination of condylar fractures. Panoramic radiography is very useful when orofacial pain is thought to arise from odontogenic cause [23].It is good as a screening modality and it does not show any soft tissue changes .

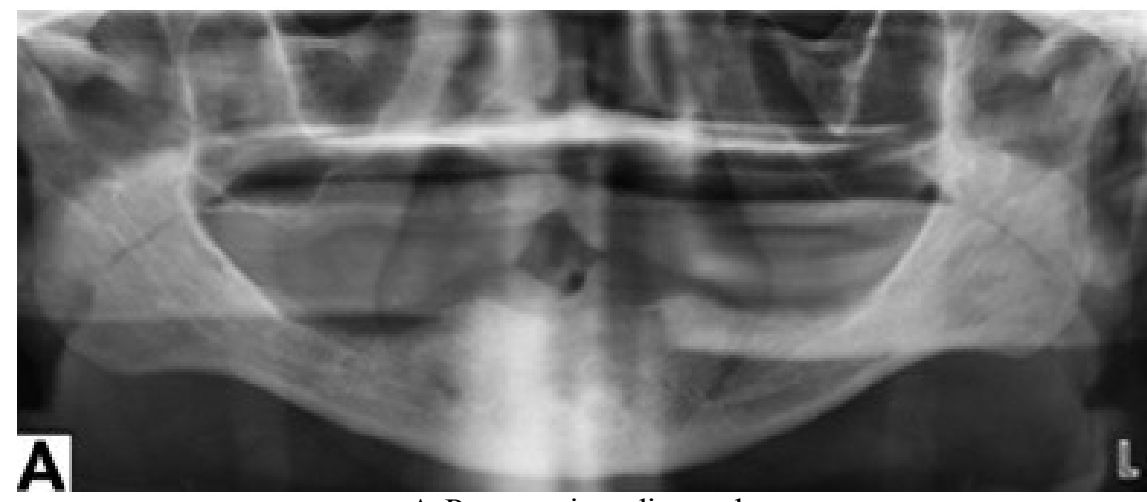

A-Panaromic radiograph
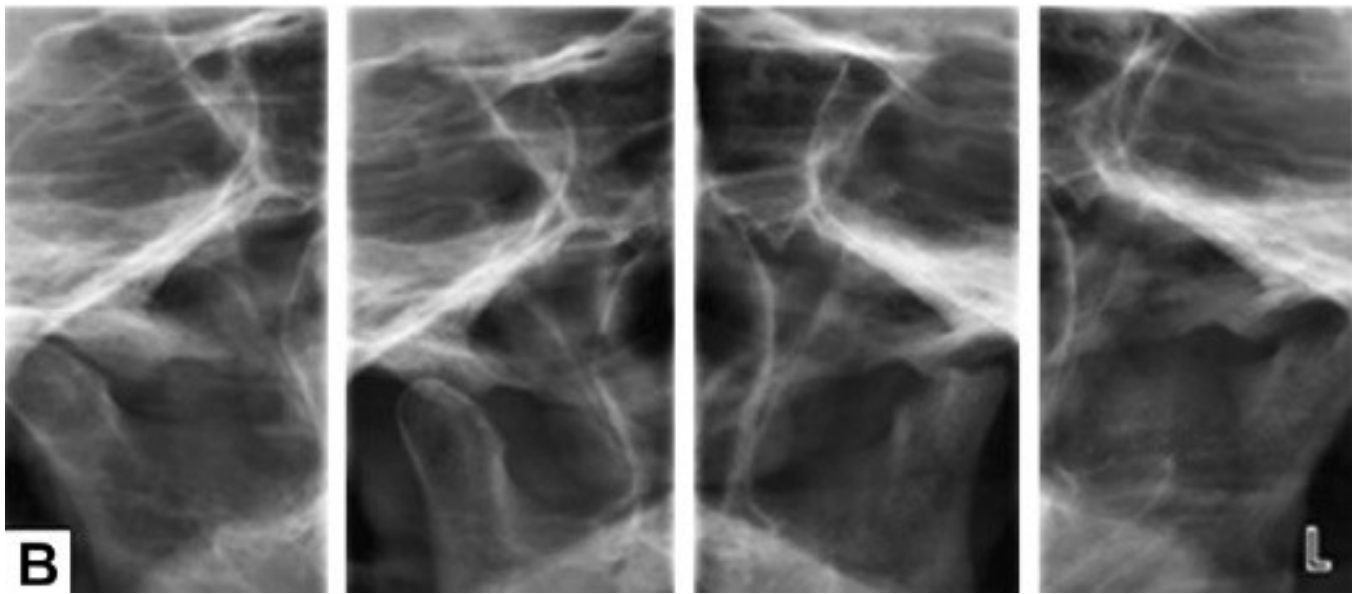

B-Panaromictmj open and closed views

\section{CONE BEAM COMPUTER TOMOGRAPHY}

Cone beam computed tomography (CT) is increasingly being used as an imagingmodality in the assessment of the TMJ.The high spatial resolution of CBCT provides superior reliability and greater accuracy than thepanaromic projections especially in the evaluation of early bone changes such as cortical erosions[24] . One of the main advantages of $\mathrm{CBCT}$ over medical $\mathrm{CT}$ and other two dimensional imaging used in dentistry is the radiation dose it uses only fraction of the radiation dose of multislice CT. CBCT has also been shown to perform better than conventional tomography, panoramic radiography, and MSCT for the evaluation of the components of the TMJ[20,25,26] 


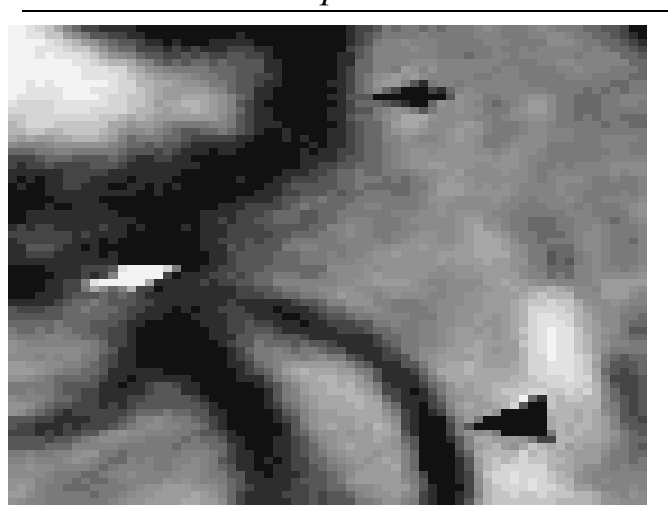

RIGHT TMJ

MAGNETIC RESONANCE IMAGE EROSION IN THE RIGHT CONDYLE
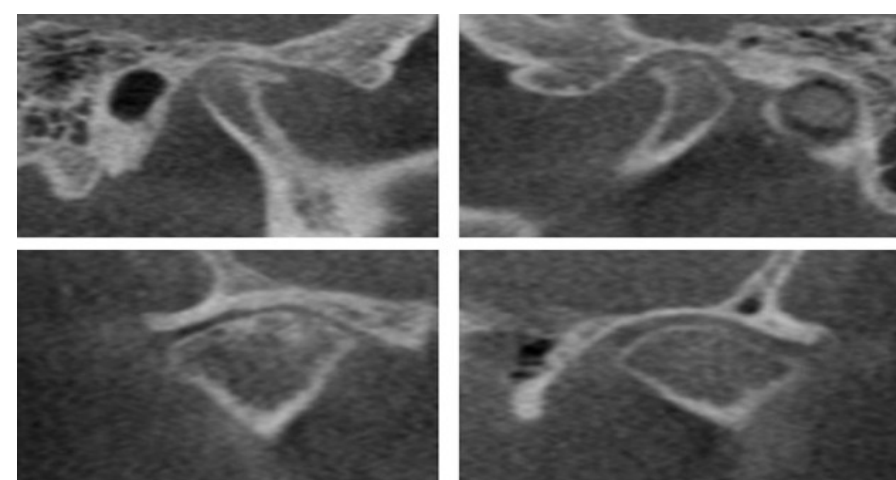

LEFT TMJ

SHOWING OSTEOPHYTE FORMATION AND SUBCHONDRAL

\section{Magnetic Resonance Imaging}

Magnetic resonance imaging (MRI) is now the primary modality for the evaluation of the temporomandibular joint (TMJ). MRI has superior soft tissue differentiation because of its improved contrast resolution over conventional tomography and CBCT[27] .MRI is commonly used to evaluate the soft tissue changes of TMJ such as the position and shape of the disc ,presence or absence of fluid within the joint (joint effusion) ,presence of loose bodies within the joint ,pannus formation (in case of inflammatory arthritides )and osseous changes .MRIis also used to detect the pathological changes of the chewing muscles.It is also routinely used to rule out the potential cause of secondary trigemenial neuralgia wich may be due to compression of the trigeminal nerve by tumors, cysts, vascular anomalies ,or due to multiple sclerosis. Evaluation for neurovascular compression with MRI has a reported high sensitivity and specificity [28,29].Headaches are another indication for advanced imaging. Headache may indicate the presence of tumors, aneurysms, orarteriovenous malformations depending on nature of theheadache [30].

Sagittal T1-weighted image shows the dislocated mandibular condyle (black arrow) anterior to the articular eminence (white arrow) and an empty glenoid fossa (black arrowhead). The disk is folded below the articular eminence.

\section{Conclusion}

Temperomandibular disorder constitute masticatory muscle disorder and tenperomandibular joint disorder. It may be due to true pathology of temperomandibular joint or involvement of masticatory muscles .Now with the advent of imaging techniques is possible to differentiate between true muscular disorders and those disorders with the pathological changes of the TMJ and the pain unrelated to dental conditions can be referred to the appropriate care provider .

\section{References}

[1] Okeson JP. Orofacial pain: guidelines for assessment, diagnosis and management. Quintessence Publishing Co Inc: Chigaco; 1996

[2] Differential diagnosis of temperomandibular and other orofacial pain disorders Jeffrey P. Okeson, DMD, Reny de Leeuw, DDS, PhD Dent Clin N Am 55 (2011) 105-120

[3] Okeson JP. Management of temporomandibular disorders and occlusion. 6thedition. St Louis (MO): The CV Mosby Company; 2008.

[4] De Leeuw R. Orofacial pain: guidelines for classification, assessment, andmanagement. 4th edition. Chicago: Quintessence Publ. Co.; 2008 .

[5] vanGrootel RJ, et al. Patterns of pain variation related to myogenous temporomandibular disorders. Clin J Pain 2005;21:154-65

[6] Mense S. The pathogenesis of muscle pain. Curr Pain Headache Rep 2003;7(6):419-25.

[7] Jeffrey P. Okeson, DMDa,*, Reny de Leeuw, DDS, PhDb Dent Clin N Am 55 (201)105- 120 differential diagnosis of temperomandibular disorders and other orofacial disorders

[8] Glaros AG, Burton E. Parafunctional clenching, pain, and effort in Temporomandibular isorders. J Behav Med 2004;27(1):91-100.

[9] Carlson CR, Okeson JP, Falace DA, et al. Comparison of psychologic and physiologicfunctioning between patients with masticatory muscle pain and matched controls. J Orofac Pain 1993;7:15-22

[10] Lund JP, Widmer CG. An evaluation of the use of surface electromyography in thediagnosis, documentation, and treatment of dental patients. J CraniomandibDisord1988;3:125-37.

[11] Klasser GD, OkesonJPThe clinical usefulness of surface electromyography in the diagnosis and treatment of temporomandibular disorders. J Am Dent Assoc 2006;137(6):763-71..

[12] Bell WE. Temporomandibular joint disease. Dallas (TX): Egan Company; 1960.

[13] Nitzan DW. 'Friction and adhesive forces'-possible underlying causes for Temporomandibular joint internal derangement. Cells Tissues Organs 2003;174(1-2):6-16.

[14] Yun PY, Kim YK. The role of facial trauma as a possible etiologic factor in Temporomandibular joint disorder. J Oral MaxillofacSurg 2005;63(11):1576-83. 
[15] Zhang ZK, Ma XC, Gao S, et al. Studies on contributing factors in Temporomandibular disorders. Chin J Dent Res 1999;2(3-4):720.

[16] Grushka M, Ching VW, Epstein JB, et al. Radiographic and clinical features oftemporomandibular dysfunction in patients following indirect trauma: a retrospectivestudy. Oral Surg Oral Med Oral Pathol Oral RadiolEndod 2007;104(6):772-80.

[17] Lipton JA, Ship JA, Larach-Robinson D. Estimated prevalence and distribution ofreported orofacial pain in the United States. J Am Dent Assoc 1993;129:115-21.

[18] Milam SB, Zardeneta G, Schmitz JP. Oxidative stress and degenerative Temporomandibularjoint disease: a proposed hypothesis. J Oral MaxillofacSurg 1998;56(2):214-23.

[19] Dworkin SF, LeResche L. Research diagnostic criteria for temporomandibular disorders:review, criteria, examinations and specifications, critique. J CraniomandibDisord 1992;6:301-55.

[20] Ahmad M, Hollender L, Anderson Q, et al. Research diagnostic criteria for Temporomandibular disorders (RDC/TMD): development of image analysis criteria andexaminer reliability for image analysis. Oral Surg Oral Med Oral Pathol Oral RadiolEndod 2009;107:844-60.

[21] Brooks SL, Brand JW, Gibbs SJ, et al. Imaging of the temporomandibular joint: aposition paper of the American Academy of Oral and Maxillofacial Radiology.Oral Surg Oral Med Oral Pathol Oral RadiolEndod 1997;83:609-18.

[22] Petersson A. What you can and cannot see in TMJ imaging - an overview relatedto the RDC/TMD diagnostic system. J Oral Rehabil 2010;37:771-8.0.

[23] Brooks SL, Brand JW, Gibbs SJ, et al. Imaging of the temporomandibular joint: a position paper of the American Academy of Oral and Maxillofacial Radiology. Oral Surg Oral Med Oral Pathol Oral RadiolEndod 1997;83:609-18.

[24] Barghan S, Tetradis S, Mallya S. Application of cone beam computed tomographyfor assessment of the temporomandibular joints. Aust Dent J 2012;57(Suppl 1):109-18.

[25] Bartling SH, Majdani O, Gupta R, et al. Large scan field, high spatial resolutionflat-panel detector based volumetric CT of the whole human skull base and formaxillofacial imaging. DentomaxillofacRadiol 2007;36:317-27.

[26] Honey OB, Scarfe WC, Hilgers MJ, et al. Accuracy of cone-beam computed tomographyimaging of the temporomandibular joint: comparisons with panoramicradiology and linear tomography. Am J OrthodDentofacialOrthop 2007;132:429-38.

[27] Curry TS, Dowdey JE, Murry RC. Christensen's physics of diagnostic radiology.4th edition. Philadelphia: Lippincott Williams \& Wilkins; 1990. p. 432-504

[28] Lacerda Leal PR, Hermier M, Souza MA. Visualization of vascular compression of the trigeminal nerve with high-resolution 3T MRI: a prospective study comparing preoperative imaging analysis to surgical findings in 40 consecutive patients who underwent microvascular decompression for trigeminal neuralgia. Neurosurgery 2011;69:15-26

[29] Lacerda Leal PR, Hermier M, Froment JC, et al. Preoperative demonstration of theneurovascular compression characteristics with special emphasis on the degree of compression, using high-resolution magnetic resonance imaging: a prospective study, with comparison to surgical findings, in 100 consecutive patients who underwent microvascular decompression for trigeminal neuralgia. ActaNeurochir 2010;152:817-25.

[30] Detsky ME, McDonald DR, Baerlocher MO, et al. Does this patient with headachehave a migraine or need neuroimaging? JAMA 2006;296:1274-83. 